\title{
Second trimester abortion- mifepristone and misoprostol or misoprostol alone?
}

\author{
Uday Patel*, Kishor Chauhan, Sonam Singhi, Medha Kanani
}

\begin{abstract}
Department of Obstetrics \& Gynecology, SBKS Medical Institute and Research Centre, Pipariya, Ta- Waghodia,
\end{abstract} Vadodara-391760, Gujarat, India

Received: 9 May 2013

Accepted: 25 May 2013

\section{*Correspondence:}

Dr. Uday Patel,

E-mail: mitrauday78@yahoo.com

(C) 2013 Patel U et al. This is an open-access article distributed under the terms of the Creative Commons Attribution Non-Commercial License, which permits unrestricted non-commercial use, distribution, and reproduction in any medium, provided the original work is properly cited.

\begin{abstract}
Background: From historical times termination of pregnancy was practiced with or without legal and social sanctions. Over the last few years, induced abortions have gained more popularity because of safe techniques and medications available. Induced abortion means willful termination of pregnancy before the period of viability. Medical abortion in the second trimester with misoprostol alone has been shown to be affective, although in comparison with the combination of mifepristone and misoprostol, misoprostol-only protocols have required higher doses, side effects are more common and the time to complete the abortion is longer.

Methods: Total of 50 eligible women were enrolled for this study and were divided in two groups of 25 each of the case group and control group. This study was conducted in the Dhiraj General Hospital, Piparia, Waghodia. Women in the case group were given Tablet Mifepristone $(200 \mathrm{mg})$ orally followed by Tablet Misoprostol (200 mcg) vaginally after 24 hours which may be repeated every 6 hrs till 5 doses. Women in control group were given Tablet Misoprostol (200 mcg) vaginally which may be repeated every 6 hrs till 5 doses.

Results: The combination of mifepristone and misoprostol is now an established and highly effective and safe method for medical method second trimester abortion. The combination of mifepristone with misoprostol significantly reduces the abortion to induction interval and also have fewer side effects and complications and also reduces the dose of misoprostol. Where mifepristone is not available or affordable, misoprostol alone has also been shown to be effective, although a higher total dose is needed and efficacy is lower than for the combined regimen. Therefore, whenever possible, the combined regimen should be used.
\end{abstract}

Conclusions: Mifepristone followed by misoprostol was more effective and has a shorter IAI and fewer side effects.

Keywords: Abortion, Mifepristone, Misoprostol, Second trimester

\section{INTRODUCTION}

The Indian Penal Code of 1860, draws heavily from the British offences against the Person Act of 1861, which criminalised causing a miscarriage unless it was done to save the woman's life. In contrast to the trend in the western world, where legislative reform of abortion laws took place in the $1960 \mathrm{~s}$ and $70 \mathrm{~s}$. In fact, it was demographers who justified legalising abortion to help curb population growth, while the medical profession advocated liberalising the law in order to reduce the high morbidity and mortality from unsafe abortions.
During $20^{\text {th }}$ century, abortion has become legal in many Western countries, but it is regularly subjected to legal challenges and restrictions by profile groups. ${ }^{1}$

There is a need for evolving a safe and effective method of terminating pregnancy in the second trimester, most recently due to the increase in the use of antenatal diagnostic procedures like amniocentesis, USG and cordocentesis.

The subject of pregnancy termination or induced abortion has evolved all over the world along with changes in the 
socio-cultural, political and economical issues. Advances in the medical and pharmaceutical technology has influenced in a big way for this evolution.

From historical times termination of pregnancy was practiced with or without legal and social sanctions. Over the last few years, induced abortions have gained more popularity because of safe techniques and medications available. Induced abortion means willful termination of pregnancy before the period of viability. ${ }^{2}$

Second trimester abortions constitute $10-15 \%$ of all induced abortions worldwide but are responsible for twothirds of major abortion-related complications. In India, 6 million abortions takes place every year, of which 4 million are induced and 2 million are spontaneous. ${ }^{3}$ Although abortions was legalized in India is 1972, illegal abortion is still (urban) five (rural) times more common than legal abortion. ${ }^{4}$

Medical abortion in the second trimester with misoprostol alone has been shown to be affective, although in comparison with the combination of mifepristone and misoprostol, misoprostol-only protocols have required higher doses, side effects are more common and the time to complete the abortion is longer. ${ }^{5}$ Higher doses (600 and $800 \mu \mathrm{g}$ ) have shown comparable successful abortion rates but are associated with higher rates of side effects. The 3hour interval is more effective than 6 hours interval. ${ }^{6}$

Unsafe abortion (2002) remains one of the leading causes of maternal death in most of developing countries. Infection rate associated with misoprostol was significantly lower than that with alternative traditional methods. If given in sufficient frequency, alone can abort a high proportion of pregnancies. Regimen of mifepristone and misoprostol has been found safe and effective in both developed and developing countries for $2^{\text {nd }}$ trimester termination of pregnancy. Best appears to be combination of mifepristone followed by misoprostol. Popular regimens includes oral dose of mifepristone 200 mg followed by 1-3 doses later with vaginal misoprostol upto $800 \mu \mathrm{g}^{7}$

\section{Aims and Objectives}

1. To evaluate the efficacy of tablet Mifepristone in combination with tablet Misoprostol in management of second trimester abortion and compare it with Misoprostol alone.

2. To observe the course and outcome of abortion in this combined regimen.

3. To study the possible side effects of these drugs.

4. To study the effective cost of both the regimens.

\section{METHODS}

\section{Case Selection}

- The present study is a prospective non-randomized comparative study done at Department of
Obstetrics and Gynecology, Dhiraj General Hospital

- Total of 50 eligible women were enrolled for this study and were divided in two groups of 25 each.

Case: Women who received Mifepristone and Misoprostol.

Control: Women who received Misoprostol alone.

\section{Inclusion Criteria}

1. Gestational age more than 16 weeks but less than 20 weeks.

2. Singleton pregnancy

3. No regular uterine contractions

4. Upto para 4.

\section{Exclusion Criteria}

1. Grand multipara

2. Scarred uterus

3. Multiple pregnancy

4. Heart disease or known contraindication to the use of study drugs

\section{Study Design}

- All the eligible patients were explained about the procedure and their written informed consent was taken.

- Women in the case group were given Tablet Mifepristone $(200 \mathrm{mg}$ ) orally followed by Tablet Misoprostol (200 mcg) vaginally after 24 hours which may be repeated every 6 hrs till 5 doses.

- Women in control group were given Tablet Misoprostol (200 mcg) vaginally which may be repeated every 6 hrs till 5 doses.

\section{Data Analysis}

- All the data were collected with the above mentioned methods and entered in to epi info version 3.5.3 and Chi- Square test was applied.

\section{RESULTS}

There were total 13 Nulliparous and 12 parous women taken in the Control group for the study. There was no woman in either nulliparous or parous group who required just 1 misoprostol tablet (1 misoprostol tablet= $200 \mu \mathrm{g}$ ) for abortion. 2 women from nulliparous group and 4 women from parous group required 2 misoprostol tablets for abortion. There were 5 nulliparous and just 1 woman from parous group who required 3 misoprostol tablets for abortion. 5 women from nulliparous group and 8 women from parous group who required 4 misoprostol tablets for abortion. There was no woman in either group who required 5 misoprostol tablets for abortion. 
Table 1: Dosage of misoprostol required in control group.

\begin{tabular}{|c|c|c|c|c|}
\hline \multirow{2}{*}{$\begin{array}{l}\text { No. of } \\
\text { Misoprostol } \\
\text { Tablets } \\
\text { Required } \\
\text { (200ug) }\end{array}$} & \multicolumn{2}{|c|}{$\begin{array}{l}\text { Nulliparous } \\
\mathrm{N}=13\end{array}$} & \multicolumn{2}{|c|}{$\begin{array}{l}\text { Parous } \\
\mathrm{N}=12\end{array}$} \\
\hline & No. & $\%$ & No. & $\%$ \\
\hline 1 & 00 & 0 & 00 & 0 \\
\hline 2 & 02 & 16.66 & 04 & 30.77 \\
\hline 3 & 05 & 41.67 & 01 & 7.69 \\
\hline 4 & 05 & 41.67 & 08 & 61.54 \\
\hline 5 & 00 & 0 & 00 & 0 \\
\hline
\end{tabular}

Table 2: Dosage of misoprostol required in case group.

\begin{tabular}{|lllll|}
$\begin{array}{l}\text { No. of } \\
\begin{array}{l}\text { Misoprostol } \\
\text { Tablets } \\
\text { Required } \\
(200 \mu g)\end{array}\end{array}$ & $\begin{array}{l}\text { Nulliparous } \\
\text { No13 }\end{array}$ & $\%$ & No. & $\begin{array}{l}\text { Parous } \\
\text { N=12 }\end{array}$ \\
\cline { 2 - 5 } & 07 & 53.84 & 07 & 58.33 \\
\hline 0 & 03 & 23.07 & 03 & 25 \\
\hline 1 & 03 & 23.07 & 02 & 16.66 \\
\hline 3 & 00 & 00 & 00 & 00 \\
\hline
\end{tabular}

Same number of women in both nulliparous and parous groups were taken for as case group as like in control group, that was 13 women in nulliparous group and 12 women in parous group.
In case group, there were 7 nulliparous women and also 7 parous women who required 0 misoprostol tablet for abortion. There were 3 nulliparous women and also 3 parous women who required 1 misoprostol tablet for abortion. 3 nulliparous and 2 parous women required 2 misoprostol tablets for abortion. There was not a single woman of either group who needed 3 misoprostol tablets for abortion.

Table 3: Average dosage of misoprostol required in both groups.

\begin{tabular}{|lll|}
\hline & $\begin{array}{l}\text { Mifepristone } \\
+ \text { Misoprostol } \\
\text { N=25 }\end{array}$ & $\begin{array}{l}\text { Misoprostol } \\
\text { Alone } \\
\mathbf{N}=\mathbf{2 5}\end{array}$ \\
\hline $\begin{array}{l}\text { Average Dosage } \\
\text { of Misoprostol } \\
\text { Required }\end{array}$ & $122 \mu \mathrm{g}$ & $696 \mu \mathrm{g}$ \\
\hline
\end{tabular}

In the case group the average dosage of Misoprostol required for abortion was $122 \mu \mathrm{g}$. The dosage of Misoprostol required for abortion in control group was $696 \mu \mathrm{gm}$.

The mean induction abortion interval in women who were given mifepristone and misoprostol both was $18.94 \pm 9.30$ hours and in the women who were given misoprostol alone was $24.29 \pm 11.53$ hours.

Requirement of Oxytocin augmentation was much less in patients receiving Mifepristone+Misoprostol as compared to those receiving Misoprostol alone.

The incidence of adverse effects was higher in patients receiving only Misoprostol than those receiving Mifepristone and Misoprostol.

Table 4: Induction abortion interval (IAI).

\begin{tabular}{|c|c|c|c|c|c|c|c|c|}
\hline \multirow{3}{*}{$\begin{array}{l}\text { IAI in } \\
\text { Hours }\end{array}$} & \multicolumn{4}{|c|}{$\begin{array}{l}\text { Mifepristone + Misoprostol } \\
\text { N=25 }\end{array}$} & \multicolumn{4}{|c|}{$\begin{array}{l}\text { Misoprostol Alone } \\
\mathbf{N}=\mathbf{2 5}\end{array}$} \\
\hline & \multicolumn{2}{|c|}{ Nulliparous $\mathbf{N}=13$} & \multicolumn{2}{|c|}{ Parous N=12 } & \multicolumn{2}{|c|}{ Nulliparous $\mathbf{N}=13$} & \multicolumn{2}{|c|}{ Parous $\mathrm{N}=12$} \\
\hline & No. & $\%$ & No. & $\%$ & No. & $\%$ & No. & $\%$ \\
\hline $0-6$ & 01 & 7.69 & 02 & 16.66 & 00 & 0 & 00 & 0 \\
\hline$>6-12$ & 04 & 30.76 & 03 & 25 & 01 & 8.33 & 00 & 0 \\
\hline$>12-18$ & 03 & 23.07 & 00 & 0 & 02 & 16.66 & 04 & 30.76 \\
\hline$>18-24$ & 00 & 0 & 02 & 16.66 & 05 & 41.66 & 03 & 23.07 \\
\hline$>24-30$ & 02 & 15.38 & 02 & 16.66 & 04 & 33.33 & 03 & 23.07 \\
\hline$>30-36$ & 03 & 23.07 & 03 & 25 & 00 & 0 & 01 & 7.69 \\
\hline$>36$ & 00 & 0 & 00 & 0 & 00 & 0 & 02 & 15.38 \\
\hline
\end{tabular}


Table 5: Mean induction abortion interval.

\begin{tabular}{|lll|}
$\begin{array}{l}\text { Duration } \\
\text { (In Hours) }\end{array}$ & $\begin{array}{l}\text { Mifepristone }+ \\
\text { Misoprostol } \\
\mathbf{N}=25\end{array}$ & $\begin{array}{l}\text { Misoprostol } \\
\text { Alone } \\
\mathbf{N}=25\end{array}$ \\
& $18.94 \pm 9.30$ & $24.29 \pm 11.53$ \\
\hline
\end{tabular}

Table 6: Distribution of patients who required oxytocin augmentation.

\begin{tabular}{|lllll|}
\hline $\begin{array}{l}\text { Oxytocin } \\
\text { Augmentation }\end{array}$ & \multicolumn{2}{l}{$\begin{array}{l}\text { Mifepristone } \\
\text { +Misoprostol } \\
\text { N=25 }\end{array}$} & \multicolumn{2}{l|}{$\begin{array}{l}\text { Misoprostol } \\
\text { Alone }\end{array}$} \\
\hline Required & 04 & 16 & 10 & 40 \\
\hline Not Required & 21 & 84 & 15 & 60 \\
\hline & $\mathrm{P}=0.0272$ & & \\
\hline
\end{tabular}

Table 7: Adverse effects of drugs.

\begin{tabular}{|c|c|c|c|c|}
\hline \multirow[t]{2}{*}{ Side Effects } & \multicolumn{2}{|c|}{$\begin{array}{l}\text { Mifepristone } \\
+ \text { Misoprostol } \\
\mathrm{N}=\mathbf{2 5}\end{array}$} & \multicolumn{2}{|c|}{$\begin{array}{l}\text { Misoprostol } \\
\text { Alone } \\
\mathrm{N}=25\end{array}$} \\
\hline & No. & $\%$ & No. & $\%$ \\
\hline Nausea & 00 & - & 01 & 04 \\
\hline Vomiting & 01 & 04 & 03 & 12 \\
\hline Diarrhoea & 00 & - & 01 & 04 \\
\hline Fever & 00 & - & 02 & 08 \\
\hline Headache & 00 & - & 00 & 00 \\
\hline Rigor & 00 & - & 04 & 16 \\
\hline Hypertonicity & 00 & - & 03 & 12 \\
\hline
\end{tabular}

Table 8: Comparison of hospital stay in both groups.

\begin{tabular}{|lllll|}
\hline $\begin{array}{l}\text { No. of } \\
\text { Days }\end{array}$ & \multicolumn{2}{l}{$\begin{array}{l}\text { Mifepristone } \\
+ \text { Misoprostol } \\
\text { N=25 }\end{array}$} & $\begin{array}{l}\text { Misoprostol } \\
\text { Alone } \\
\text { N=25 }\end{array}$ \\
\cline { 2 - 5 } & No. & $\%$ & No. & $\%$ \\
\hline$\leq 3$ & 12 & 48 & 13 & 52 \\
\hline $4-6$ & 11 & 44 & 10 & 40 \\
\hline$>6$ & 02 & 08 & 02 & 08 \\
\hline
\end{tabular}

Comparative hospital stay in patients receiving Mifepristone +Misoprostol was more or less similar to patients receiving Misoprostol alone.

Table 9: Mean cost of drugs used in the study.

\begin{tabular}{|lll|}
\hline Drugs Used & $\begin{array}{l}\text { Mifepristone } \\
\text { +Misoprostol }\end{array}$ & $\begin{array}{l}\text { Misoprostol } \\
\text { Alone }\end{array}$ \\
\hline Mifepristone & Rs.395 & Rs.0 \\
\hline Misoprostol & Rs.12.05 & Rs.68.73 \\
\hline Oxytocin & Rs.96.8 & Rs.242 \\
\hline Total Cost & Rs.503.85 & Rs.310.73 \\
\hline
\end{tabular}

The mean cost of the drugs in case group was Rs 503.85 and in control group was Rs.310.73.

Table 10: Type of abortion occurring by both the groups.

\begin{tabular}{|lll|}
\begin{tabular}{|l} 
Type of \\
Abortion
\end{tabular} & $\begin{array}{l}\text { Mifepristone } \\
+ \text { Misoprostol } \\
\mathbf{N}=\mathbf{2 5}\end{array}$ & $\begin{array}{l}\text { Misoprostol } \\
\text { Alone } \\
\mathbf{N}=\mathbf{2 5}\end{array}$ \\
\hline Complete & 25 & 21 \\
\hline Incomplete & 00 & 04 \\
\hline
\end{tabular}

It was observed that complete abortion occurred in 25 patients receiving mifepristone and misoprostol both and in 21 patients receiving misoprostol alone. There was no patient who had incomplete abortion after receiving mifepristone and misoprostol and 4 patients receiving misoprostol alone.

\section{DISCUSSION}

Second trimester pregnancy termination is still a complicated procedure in developing countries especially in rural areas.

There is constant search going on for an ideal method which is $100 \%$ reliable, safe and cheap.

The IAI, success rate, hospital stay duration, side effects, and costs are compared between the two groups.

$>$ There was significant difference in the IAI in both the groups, the mean IAI of 18.94 hours for Group A, whereas in Group B IAI is 24.29 hours.

$>$ There was also difference in the success rate and hospital stay duration. The hospital stay was longer in Group B than Group A.

$>$ Side effects were also seen more in Group B than Group A.

The combination of oral mifepristone $200 \mathrm{mg}$ pretreatment, followed by vaginally misoprostol, provides a non-invasive effective regimen for medical second trimester termination of pregnancy and significantly reduces the induction to abortion interval and lesser side effects and good patient compliance. The side effects observed were actually directly associated with the dosage of misoprostol.

This method can be used in an outpatient clinic or primary health centre where facilities for surgical evacuation are not available. The doctors with back up facility who are not trained in MTP's can perform this procedure. In case of any problem like retained products, suspected abortion failure, heavy bleeding per vaginum the patient can be referred to health facilities for surgical evacuation are available. With this procedure morbidity 
and mortality due to illegal abortions can be markedly reduced.

\section{CONCLUSION}

During the last decade, medical methods for second trimester induced abortion have been considerably improved and become safe and more accessible. Today, in most cases, safe and efficient medical abortion services can be offered or improved by minor changes in existing health care facilities.

Because of the potential for heavy vaginal bleeding and serious complications, it is advisable that second trimester terminations take place in a health care facility where blood transfusion and emergency surgery (including laparotomy) are available. The combination of mifepristone and misoprostol is now an established and highly effective and safe method for medical method second trimester abortion. The combination of mifepristone with misoprostol significantly reduces the abortion to induction interval and also have fewer side effects and complications and also reduces the dose of misoprostol. Where mifepristone is not available or affordable, misoprostol alone has also been shown to be effective, although a higher total dose is needed and efficacy is lower than for the combined regimen. Therefore, whenever possible, the combined regimen should be used. Efforts should be made to reduce unnecessary surgical evacuation of the uterus after expulsion of the fetus.

So among the two methods, mifepristone followed by misoprostol was more effective and has a shorter IAI and fewer side effects. But in fact, both are feasible as far as end results are concerned.

\section{Funding: None \\ Conflict of interest: None declared \\ Ethical approval: The study was approved by the Institutional Ethics Committee}

\section{REFERENCES}

1. The last abortion Clinic Frontline 2005. Available at www.pbs.org/wgbh/psges/frontline/clinic. Accessed 22 April 2013.

2. Chaudhary SK. Pregnancy termination. In: Chaudhary SK, editor. Practice of fertility control. $5^{\text {th }}$ edition. London: Churchill Livingstone Pvt. Ltd, 2001;268-69.

3. Chhabra R, Nuna SC. Abortion in India - an overview. Delhi: Ford foundation; 1994.

4. Karkal M. Abortion laws and the abortion situation in India. Reprod Genet Eng 1991;4:223-30.

5. Caliskan E, Dilbaz S, Doger E, Ozeren S, Dilbaz B. Randomized comparison of 3 misoprostol protocols for abortion induction at 13-20 weeks of gestation. J Reprod Med 2005;50(3):173-80.

6. Tang OS, Gemzell-Danielsson K, Ho PC. Misoprostol: Pharmacokinetic profiles, effects on the uterus and side-effects. Int J Gynaecol Obstet 2007;99:160-7.

7. Jonathan S. Berecl. "Novak's Gynecology": Thirteenth edition: Lippincott Williams \& Wilkins publication, 2002:279-81.

DOI: $10.5455 / 2320-1770 . i j r \operatorname{cog} 20130911$

Cite this article as: Patel U, Chauhan K, Singhi S, Kanani M. Second trimester abortion- mifepristone and misoprostol or misoprostol alone? Int J Reprod Contracept Obstet Gynecol 2013;2:315-9. 